J. Lake Sci.(湖泊科学), 2019, 31(4): 907-918

DOI 10. 18307/2019. 0416

(c) 2019 by Journal of Lake Sciences

\title{
湖泊沉积物一水界面磷的迁移转化机制与定量研究方法
}

\author{
陈 洁 ${ }^{1,2}$, 许 海 $^{1 * *}$, 詹 㝵 $^{2}$, 朱广伟 ${ }^{1}$, 秦伯强 ${ }^{1}$, 张运林 ${ }^{1}$ \\ (1: 中国科学院南京地理与湖泊研究所湖泊与环境国家重点实验室,南京 210008) \\ $(2$ : 江南大学环境与土木工程学院,无锡 214122)
}

\begin{abstract}
摘 要: 湖泊磷循环主要指磷在沉积物、上覆水和生物体间的迁移转化,而沉积物一水界面磷的迁移转化作为富营养湖 泊磷循环的关键过程, 备受关注. 本文就国内外研究进展, 综述了磷在上覆水、沉积物中的赋存形态和生物有效性, 沉积 物一水界面磷迁移转化的机制与定量研究方法. 探讨沉积物性质、环境因子和生物特性对界面磷迁移的驱动机制, 以及磷 在浅水湖泊、深水湖泊中迁移转化机制的差异, 指出现阶段迁移机制的研究多集中在单因素和定性化方面, 而对多因素 和定量化的研究还相对缺乏, 未来可深人探究多因素耦合作用下磷的迁移规律. 分析了野外调查、模拟实验、质量衡算和 模型等研究方法的优缺点及适用情况, 提出未来可将野外调查、模拟实验和模型法相结合, 借助野外调查识别磷的迁移 过程, 模拟实验验证磷迁移的机制, 并以野外调查和模拟实验的数据和结论为基础, 构建模型量化具体迁移过程及其对 湖泊磷循环的贡献, 从而全面认识磷迁移转化规律. 最后, 提出了未来湖泊沉积物一水界面磷迁移研究需要关注的几个 方面.
\end{abstract}

关键词: 沉积物一水界面;湖泊;迁移;转化;内源磷; 机制

\section{Mechanisms and research methods of phosphorus migration and transformation across sediment-water interface}

\author{
CHEN Jie ${ }^{1,2}$, XU Hai ${ }^{1 * *}$, ZHAN Xu ${ }^{2}$, ZHU Guangwei ${ }^{1}$, QIN Boqiang ${ }^{1} \&$ ZHANG Yunlin ${ }^{1}$ \\ (1: State Key Laboratory of Lake Science and Environment, Nanjing Institute of Geography and Limnology, Chinese Academy \\ of Sciences, Nanjing 210008, P.R. China) \\ (2: School of Environment and Civil Engineering, Jiangnan University, Wuxi 214122, P.R.China)
}

\begin{abstract}
Phosphorus (P) cycling in lake is the migration and transformation of $\mathrm{P}$ between sediment, water and organisms. Special attention has been paid to $\mathrm{P}$ migrate and transformation between sediment and water, the typical process of $\mathrm{P}$ cycling in eutrophic lakes. Through the summary of studies at home and abroad, this paper reviews the fraction and bio-availability of $\mathrm{P}$ in water and sediment, the mechanisms and research methods of $\mathrm{P}$ migration and transformation across the sediment-water interface, and the effecting factors of $\mathrm{P}$ migrate, such as sediment properties, environmental factors and biological factors. In view of the fact that most of current research focuses on single-factor simulation experiments, conducting in-situ multi-factor experiments to explore the main mechanisms of different lakes in the future. Moreover, the main research methods of experiment in this field were summarized and compared. Different methods should be combined together to examine the cycling of P. Such as using the field observation to identify the migration of $\mathrm{P}$, the simulation experiment to analyze main mechanisms, and the model to quantitative the mass balance of $\mathrm{P}$. Finally, demands and challenges about $\mathrm{P}$ migrate and transformation in future research are proposed.
\end{abstract}

Keywords: Sediment-water interface; lakes; migration; transformation; internal phosphorus; mechanisms

湖泊具有调节水量、维持生物多样性以及提供水源等生态功能,但受人类活动的影响, 湖泊富营养化日

* 国家自然科学基金项目(41573076,41661134036)、国家水体污染控制与治理科技重大专项( 2017ZX07203-001)、 中国科学院南京地理与湖泊研究所 “一三五” 战略发展规划项目 (NIGLAS2017GH04) 和江苏省研究生科研与实践 创新计划项目 (SJCX17-0501) 联合资助. 2018-11-19 收稿; 2019-01-02 收修改稿. 陈洁 (1995 ), 女, 硕士研究 生;E-mail:chen95jie@163.com.

** 通信作者; E-mail:hxu@ niglas.ac.cn. 
趋严重. 磷被认为是湖泊富营养化的主要限制因子 ${ }^{[1-5]}$, 这一论断导致控磷措施成为欧美国家湖泊富营养化 的主要管理策略 ${ }^{[6]}$, 并使一些湖泊的水质得到改善. 然而控磷措施在很多大型浅水湖泊并不成功 ${ }^{[7]}$, 这引起 人们对湖泊磷的动态和内源磷释放的广泛关注 ${ }^{[8-9]}$. 磷按来源可分为外源磷和内源磷, 外源磷经地表径流、 大气沉降等途径进人湖泊后, 经吸附、络合、絮凝、沉降等作用埋藏于沉积物, 成为潜在污染源 ${ }^{[3]}$. 当沉积物一 水界面环境或生物因素改变时, 内源磷可能会通过解吸、溶解或生物分解等过程再次进人上覆水 ${ }^{[1-3]}$. 因此, 当外源磷经截污或生态修复等举措得到有效控制时, 内源磷的释放会推迟湖泊水质恢复, 延缓湖泊富营养 化的治理效果 ${ }^{[4,6-8]}$.

沉积物中内源磷主要来源于湖泊中颗粒态磷、溶解态磷 (被矿物颗粒吸附后) 以及生物体中有机磷的沉 降. 磷在沉积物一水界面的迁移转化过程作为富营养湖泊磷循环的关键过程 ${ }^{[2]}$, 受沉积物性质、界面环境和 生物特性等因素的共同影响 ${ }^{[1-6]}$. 经典磷循环理论认为磷会被铁(氢)氧化物吸附或生成 $\mathrm{FePO}_{4}$ 沉淀, 磷释放 主要受溶解氧和氧化还原电位控制 ${ }^{[5-6]}$, 然而, 不同湖泊磷迁移的主导机制不尽相同. 谢平 ${ }^{[10]}$ 在探讨浅水湖 泊内源磷释放的主要机制时认为, $\mathrm{pH}$ 比溶解氧的影响更大, 浮游植物光合作用会影响水体及表层沉积物的 $\mathrm{pH}$, 从而促进沉积物释磷. 近年来, 国内外学者对沉积物一水界面磷的迁移转化机制开展了大量的研究, 对 环境及生物等因素的影响机制有了一定的认识. 如溶解氧会影响有机质分解速率和磷的赋存形态 ${ }^{[3]}, \mathrm{pH}$ 会 影响磷与 $\mathrm{Fe} 、 \mathrm{Al}$ 等金属的结合 ${ }^{[5]}$, 温度会影响微生物活性和有机质分解速率 ${ }^{[3-5]}$, 进而影响磷的迁移转化等. 然而, 现阶段的研究多集中于单因素定性方面, 对于不同湖泊中各因素对磷迁移转化的相对重要性仍不 清楚.

本文根据国内外研究进展, 综述了磷在上覆水、沉积物中的赋存形态和生物有效性, 沉积物一水界面磷 迁移的机制及深水湖泊与浅水湖泊磷迁移驱动机制的差异; 对比了沉积物一水界面磷迁移研究方法的优缺 点和适用条件; 总结以往研究经验, 指出未来研究方向, 以期全面认识磷的迁移规律与机制, 为预防湖泊生 态退化和修复富营养化湖泊提供理论依据和科学支持.

\section{1 湖泊磷循环}

\section{1 湖泊中磷的赋存形态}

湖泊上覆水中磷主要以溶解态和颗粒态存在, 溶解态磷包括磷酸盐 $\left(\mathrm{PO}_{4}^{3-} 、 \mathrm{HPO}_{4}^{-}\right.$和 $\left.\mathrm{H}_{2} \mathrm{PO}_{4}^{-}\right)$、焦磷酸盐、 偏磷酸盐、聚磷酸盐、金属结合态磷 (如 Fe-P、Al-P) 以及低价态磷酸盐 ( 如亚磷酸盐、次磷酸盐 $)^{[11-14]}$. 颗粒 态磷形式多样, 主要包括生物体中的磷; 细胞中 DNA、RNA、ADP 和 ATP 等高能磷酸盐; 矿物结合态磷; 颗粒 物吸附磷以及残屑中的矿物晶体型磷等 ${ }^{[11]}$. 目前, 试验常利用钿酸盐比色法测定总磷 (TP)、溶解性总磷 (DTP) 和溶解性活性磷 (SRP) $)^{[5]}$, 并用 TP 与 DTP 差值计算颗粒态磷 (PP), 进而反映上覆水中磷的存在状 况和迁移特性. 然而常规的钿酸盐比色法用硫酸钾高温消解其他形态的磷, 不可避免地忽视了上覆水中其 他形态的磷 ${ }^{[8]}$, 如低价态磷酸盐. 近年来, 随着现代分析技术的发展, 越来越多的磷被陆续检测出, 如离子色 谱 $(\mathrm{IC})$ 可以检测次磷酸盐、亚磷酸盐和正磷酸盐 ${ }^{[13]}$, 核磁共振 $\left({ }^{31} \mathrm{P}-\mathrm{NMR}\right)$ 可以检测焦磷酸盐、多聚磷酸盐、 磷酸单酯及磷酸酯等 ${ }^{[11]}$. 借助现代分析技术检测上覆水中磷的赋存形态、分布状况和迁移特征, 为深人研 究富营养湖泊磷迁移机制提供技术保障.

沉积物作为湖泊中磷的蓄积库, 磷的赋存形态多样, 主要可分为无机磷和有机磷 ${ }^{[12]}$. 其中, 无机磷主要 以金属结合态磷、矿物表面吸附的可交换态磷和间隙水中溶解态磷等形式存在 ${ }^{[11]}$; 有机磷主要指存在于生 物体中的颗粒态有机磷和由膦脂、磷酸糖类、磷酸酯和膦酸盐等组成的溶解态有机磷 ${ }^{[12]}$. 现阶段, 常采用顺 序提取法对沉积物中的磷进行形态分析, 该法借助化学剂的浸提特性逐级分离无机磷 ${ }^{[14]}$, 如 Hupffer 法将沉 积物中的磷分为弱吸附态磷 $\left(\mathrm{NH}_{4} \mathrm{Cl}-\mathrm{P}\right)$ 、可还原态磷 ( BD-P)、铝/铁结合态磷 ( $\left.\mathrm{NaOH}-\mathrm{srP}\right)$ 、聚磷/有机磷 $(\mathrm{NaOH}-\mathrm{nr} \mathrm{P})$ 、钙结合态磷 ( HCl-P) 和残渣态磷 ( rest-P) 等 ${ }^{[16-17]}$. 由于提取试剂、程序的不同, 测定结果不具有 广泛可比性, 欧洲标准化委员会于 2001 年颁布了 SMT 协议作为淡水湖泊沉积物磷形态分析的参考, 该法将 磷分为 TP、无机磷 (IP) 、有机磷 ( OP) 、铁/铝/锰结合态磷 ( NaOH-P)、HCl-P ${ }^{[4-5]}$. SMT 法操作简单, 易于重 复, 并能估计磷的潜在来源, 因而被广泛使用 ${ }^{[14]}$. 如 Liu 等 ${ }^{[15]}$ 用 SMT 法测定了滇池沉积物磷的赋存形态. 此 外, 我国学者改进了国外主流提取方案以适应国内富营养化湖泊沉积物磷形态研究, 如改进的 Ruttenberg 
法 ${ }^{[18]}$ 将磷分为可交换态磷 ( Ex-P)、铝结合态磷 ( Al-P)、闭蓄态磷 ( Oc-P)、自生钻磷 ( Ca-P) 和 OP; 改进的 SEDEX 法 ${ }^{[19]}$ 将磷分为 TP、IP、原生碎屑磷 (DAP)、Ca-P、OP、不稳态磷和铁结合态磷 ( Fe-P ). 有机磷作为潜 在生物有效磷, 结构复杂, 常规的顺序提取法难以分离鉴定, 需借助分子光谱、酶解法等技术手段进一步分 离检测 ${ }^{[12]}$.

间隙水作为沉积物与上覆水间磷交换的介质,如何无干扰地获取间隙水一直是学术界关注的问题. 现 阶段间隙水获取方法有离心法、Rhizon 法、薄膜渗析法 (Peeper)、薄膜扩散平衡技术 (DET) 和薄膜梯度扩散 技术 (DGT) 等, 其中 DGT 技术作为一种原位被动采样技术, 避免了主动采样操作繁琐、误差较大的缺点, 且 比 Peeper、DET 等技术具有更高的分辨率、更短的平衡时间,因此被广泛应用 ${ }^{[16-17]}$.

\section{2 磷的生物有效性}

水生生物优先利用水体中的可溶性活性磷 (SRP), 当 SRP 浓度低时, 生物可通过酶解、水解等途径将有 机磷等其他形态的磷转化为生物有效磷 ${ }^{[21]}$. 沉积物中的磷会影响湖泊富营养化水平,但并非所有形态的磷 都能直接作用于湖泊初级生产力, 这取决于磷的生物有效性. 生物有效磷 (BAP) 是指直接或潜在能被水生 生物利用的活性磷 ${ }^{[19]}$, 当生物直接可利用磷缺乏时, 潜在生物可利用磷通过物理化学或生物等过程转化为 溶解态磷, 从而影响湖泊初级生产力 ${ }^{[19]}$. 目前, 生物有效磷所包含的磷形态尚没有统一规定, 王敬富等 ${ }^{[16]}$ 认 为 $\mathrm{NH}_{4} \mathrm{Cl}-\mathrm{P}$ 和 BD-P 是生物有效磷的主要来源, 朱广伟等 ${ }^{[18]}$ 将 Ex-P 和 Fe-P 划分为生物有效磷, 高春梅 等 ${ }^{[19]}$ 将不稳态磷、Fe-P 和 OP 界定为生物有效磷. 总之, 常将活性无机磷 ( Ex-P、Fe-P 等) 和可降解有机磷作 为生物有效磷的主要来源.

现阶段,藻类培养法、化学试剂法、铁氧化物滤纸法和 DGT 技术均可用于测定沉积物中的 BAP 含量 ${ }^{[22]}$. 藻类培养法测定 BAP 虽然可靠, 但耗时较长, 不适合常规监测, 目前常用化学试剂法测定 ${ }^{[19]}$, 根据提取试剂 和程序的不同, 沉积物 BAP 可分为水溶性磷 (WSP)、藻可利用磷 (AAP) 和 $\mathrm{NaHCO}_{3}$ 提取磷 (Olsen-P) ${ }^{[16]}$. 沉 积物磷的生物有效性与湖泊富营养化风险密切相关, 研究发现, 污染程度较高的湖区 BAP 含量较高, 如红枫 湖重污染湖区后五、大坝的 BAP 含量比其他湖区高 ${ }^{[16]}$; 太湖 BAP 含量呈北高南低, 西高东低的梯度分布, 也与湖泊富营养程度显著相关 ${ }^{[20]}$. 野外调查发现, 太湖表层沉积物 AAP 含量与水体叶绿素 a 浓度呈显著正 相关, 说明表层沉积物中 AAP 含量会影响夏季蓝藻水华的暴发 ${ }^{[18]}$. 徐望龙等 ${ }^{[22]}$ 发现与化学试剂法相比, DGT 技术测定的生物有效磷能更好地与藻类生长状况拟合, 这验证了 DGT 技术测定生物有效磷的可行性.

\section{3 湖泊磷循环}

磷作为生物物质合成和能量传输的必要元素, 浓度变化会影响生物的生长, 甚至是种群的演替 ${ }^{[18]}$. 正 常的湖泊磷循环是保障湖泊生态功能的前提, 磷可通过大气沉降、地表径流及污染输人等途径流人湖泊, 然 后或在沉积物、上覆水和生物体间迁移转化, 或通过河流流出、生物捕获和沉积等途径流出湖泊 ${ }^{[2-3,24]}$ (图 1). 狭义的湖泊磷循环是指磷在沉积物、上覆水和生物体间迁移转化. 上覆水中的磷或被生物吸收以有机磷 的形式储存在生物体, 参与磷的生物循环; 或被颗粒物吸附通过沉降、沉积等过程向沉积物迁移 ${ }^{[3]}$. 生物体 中的磷既能通过食物链参与生物循环, 也能通过水生动物排泄或水生动植物衰亡分解重新回到上覆水, 或 是随未分解的有机质沉降至沉积物 ${ }^{[24]}$. 沉积物中的磷在环境因子 (如温度、 $\mathrm{pH}$ 、氧化还原电位、扰动等) 和生 物 (浮游藻类、水生动植物等) 的影响下 ${ }^{[3-5]}$, 以间隙水为媒介向上覆水和生物体迁移.

沉积物一水界面是湖泊磷地球化学循环的重要场所, 频繁地发生着磷的迁移转化. 通常, 沉积物中磷含 量远大于上覆水, 仅少量磷的释放就会显著增加上覆水磷含量, 因此, 沉积物中磷向上覆水迁移作为富营养 湖泊磷循环的关键过程备受关注 ${ }^{[2]}$. 沉积物中的磷可通过静态释放或动态释放向上覆水迁移 ${ }^{[25]}$. 静态释放 将间隙水中溶解态磷通过浓度梯度扩散向上覆水迁移 ${ }^{[25-26]}$. 动态释放是由表层沉积物再悬浮引起的磷迁 移, 再悬浮是水动力扰动 (风浪、潮汐等)、生物扰动 (河蚬、摇蚊等) 和人类活动 (底泥疏浚、拖网捕捞、帆船 航行等) 相互作用的结果, 通常易再悬浮的颗粒物包括生物排泄物和有机质降解产物等 ${ }^{[25-27]}$. 再悬浮可以促 进间隙水中溶解态磷的扩散、沉积物中可交换态磷的解吸以及有机磷的矿化, 进而引起上覆水磷含量的增 加; 此外, 扰动复氧也会改变底泥性质, 如氧化还原电位、 $\mathrm{pH}$ 和微生物活性等, 从而影响磷在沉积物和上覆 水间的分配平衡 ${ }^{[26-28]}$.

除环境因子外, 生物也会影响磷在沉积物和上覆水间的分配. 有机质矿化分解时, 好氧微生物以溶解氧 


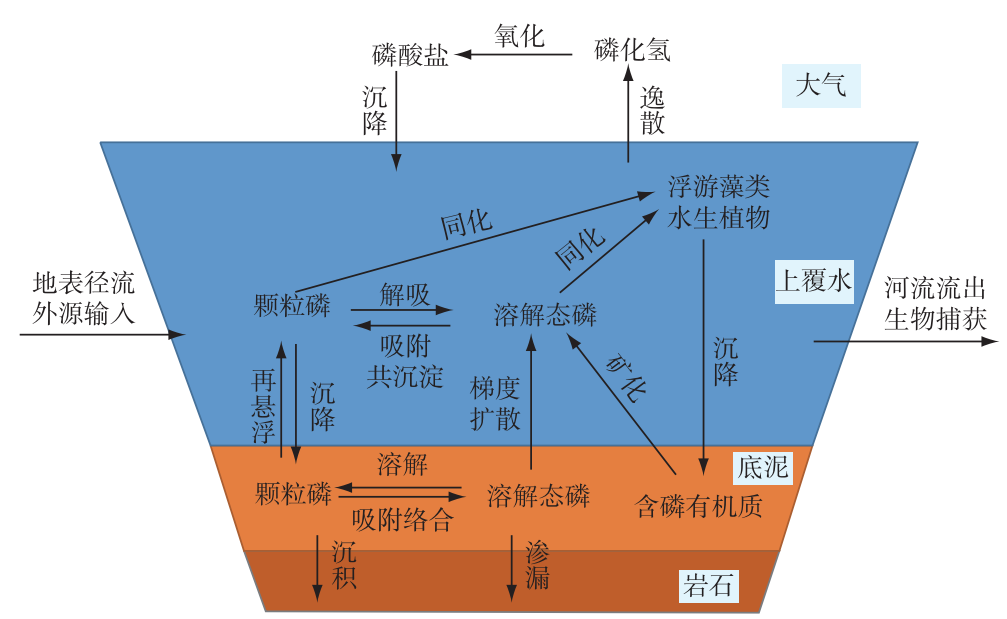

图 1 湖泊磷循环过程

Fig.1 The process of phosphorus cycling in lake

为电子受体, 氧化分解含磷有机质; 当溶解氧不足时, 厌氧微生物利用 $\mathrm{SO}_{4}^{2-} 、 \mathrm{NO}_{3}^{-}$为电子受体厌氧分解含磷有 机质,生成溶解态磷通过梯度扩散释放或被矿物颗粒吸附 ${ }^{[29-30]}$. 此外, 水生植物也会影响沉积物中磷的迁 移, 如浮游植物能够直接利用上覆水的生物有效磷 ${ }^{[1]}$, 间接影响沉积物磷的迁移; 沉水植物还能通过根系直 接利用沉积物中的磷或通过根系泌氧改变根际微环境, 为微生物的生长和代谢营造良好的生存环境 ${ }^{[3,31]}$.

\section{2 沉积物一水界面磷迁移转化的机制}

沉积物一水界面作为湖泊磷循环的重要场所, 受沉积物性质、环境因子和生物等影响, 磷从沉积物 (固 相) 向间隙水 (液相) 迁移, 进而向上覆水释放, 该过程作为富营养湖泊磷循环的关键过程, 受到学术界广泛 关注. 前人研究发现, 天然湖泊中只有 $5 \% \sim 10 \%$ 的磷是溶解态磷 ${ }^{[5]}$, 其余部分会被悬浮颗粒吸附而沉降, 进 而缓解湖泊富营养化进程. 但在环境和生物等因素的影响下, 沉积物中的磷会再活化 (解吸或溶解) 而重新 回到上覆水,这期间不同湖泊的主导影响机制有所差异.

\section{1 沉积物性质对沉积物一水界面磷迁移转化的影响}

沉积物的粒径结构、有机质组成、微生物和铁的含量均会影响界面磷迁移. 沉积物的粒径大小会影响再 悬浮的程度 ${ }^{[32]}$, 受湖泊地形和水动力的影响 ${ }^{[5]}$, 沉积物粒径可分为黏粒 $(<4 \mu \mathrm{m})$ 、粉砂粒 $(4 \sim 63 \mu \mathrm{m})$ 和砂 砾 $(>63 \mu \mathrm{m})^{[27]}$, 通常粒径越小, 比表面面积越大, 吸附能力也越强, 释放的磷更易被重新吸附. 李乐等 ${ }^{[32]}$ 发 现滇池间隙水 DTP、SRP 浓度与沉积物黏粒、粉砂粒的比重呈显著负相关, 这一定程度上说明细颗粒物越 多,则间隙水磷含量越少, 沉积物磷的释放越少.

沉积物中有机质包含脂肪酸、腐殖质和蛋白质等成分 ${ }^{[30]}$, 主要来源于湖泊中藻类、动植物残体的沉积. 有机质矿化作为湖泊磷循环的重要驱动力 ${ }^{[29]}$, 其产物会不同程度地影响磷的吸附速率和吸附量, 如腐殖质 能在无机物表面形成胶膜, 减缓磷的迁移速率; 富里酸会与磷酸盐竞争吸附而影响磷的迁移 ${ }^{\left[{ }^{[0]}\right.}$. 此外, 有机 质还能与 $\mathrm{Fe} 、 \mathrm{Al}$ 等金属形成复合体, 促进磷的吸附. 调查发现洱海沉积物磷释放潜能与有机质含量呈正相 关,且轻组有机质含量会影响沉积物磷的最大释放速率和释放量 ${ }^{[28]}$.

微生物作为湖泊生态的重要组成部分, 会促进沉积物磷的释放. 一方面微生物矿化分解有机磷, 另一方 面微生物代谢过程分泌的有机酸会降低微环境的 $\mathrm{pH}^{[33]}$. 钱燕等 ${ }^{[34]}$ 借助湿热灭菌 $+40 \%$ 甲醛溶液构建无菌 的体系, 发现灭菌沉积物会吸附上覆水的磷, 而未灭菌的沉积物由于微生物的活动而促进沉积物释放磷.

普遍认为铁磷耦合是影响磷迁移的主要机制, 即铁的还原会导致磷的释放. 龚梦丹等 ${ }^{[35]}$ 利用 $\mathrm{ZrO}$ Chelex DGT 技术分析太湖、巢湖、鄱阳湖和洞庭湖沉积物活性铁和磷的含量, 发现两者含量同步变化且显著 正相关, 并利用模拟实验验证了铁磷耦合关系. Chen 等 ${ }^{[1]}$ 模拟实验发现太湖藻华暴发过程中铁、磷浓度也 
呈现类似变化. 因此,有学者提出将 $\mathrm{Fe} / \mathrm{P}$ 为 15 作为沉积物磷是否明显释放的判断标准, $\mathrm{Fe} / \mathrm{P}$ 作为衡量铁 (氢) 氧化物表面吸附磷酸根自由点位多少, 值越低,则越利于沉积物释磷 ${ }^{[35]}$.

\section{2 环境因子对沉积物一水界面磷迁移转化的影响}

沉积物一水界面磷迁移转化受诸多环境因子的影响, 如溶解氧 ${ }^{[32]} 、 \mathrm{pH}^{[36]}$ 、温度 ${ }^{[37]}$ 和硝酸盐等 ${ }^{[38-41]}$. 天 然湖泊磷的迁移是多种因素共同作用的结果, 且不同湖泊主导机制不尽相同. $\mathrm{Wu}$ 等 ${ }^{[4]}$ 正交实验发现玄武湖 沉积物磷释放受溶解氧的影响较大, 其次是温度和 $\mathrm{pH}$. 溶解氧作为界面磷迁移的重要驱动因子, 通过影响 $\mathrm{pH}$ 、氧渗透深度、微生物新陈代谢、硫的氧化还原以及有机质的降解间接影响磷的迁移 ${ }^{[17]}$. 前人发现厌氧更 利于沉积物中磷的释放 ${ }^{[5]}$, 厌氧或缺氧时, $\mathrm{Fe}^{3+}$ 易还原为 $\mathrm{Fe}^{2+}$, 促进 $\mathrm{Fe}(\mathrm{OH})_{3}$ 吸附的磷或 $\mathrm{Fe}-\mathrm{P}$ 的释放 ${ }^{[12]}$. 红 枫湖 (深水湖泊) 沉积物厌氧培养时主要释放 $\mathrm{NaOH}-\mathrm{P}$ 和 $\mathrm{OP}$, 因为厌氧会加速 $\mathrm{SO}_{4}^{2-}$ 的还原, 生成 $\mathrm{H}_{2} \mathrm{~S}$ 与 $\mathrm{Fe}^{2+}$ 结合, 促使了 $\mathrm{NaOH}-\mathrm{P}$ 释放; 厌氧微生物还能促进 OP 转化 ${ }^{[17]}$. 太湖、滇池和西湖等湖泊的模拟实验中也观 察到类似现象 ${ }^{[5,42]}$. 但有学者发现当沉积物富含有机质,好氧环境更利于磷的释放, 可能由于含磷有机质矿 化分解会促进磷的释放 ${ }^{[3]}$. 但沉积物中有机磷含量一般较少, 且副产物腐殖质具有吸附性, 使得好氧时磷的 释放量并不大.

研究表明, 藻类光合作用 ${ }^{[43]}$ 、微生物代谢产物和外源污染均会影响湖泊 $\mathrm{pH}^{[36]} \cdot \mathrm{pH}$ 会干扰离子交换过 程, 进而影响磷与 $\mathrm{Fe} 、 \mathrm{Al} 、 \mathrm{Ca}$ 等金属的结合 ${ }^{[39]}$. 研究发现, $\mathrm{pH}$ 在钙质和非钻质湖泊中的影响效果存在差异, 非钙质湖泊中, $\mathrm{PO}_{4}^{3-}$ 与 $\mathrm{OH}^{-}$竞争吸附促使 $\mathrm{NaOH}-\mathrm{P}$ 释放, 但游离的磷在钙质湖泊中会被 $\mathrm{CaCO}_{3}$ 吸附或与 $\mathrm{Ca}(\mathrm{OH})_{2}$ 共沉淀 ${ }^{[36]}$. 实验发现偏酸、偏碱均利于玄武湖沉积物磷释放, 酸性促进 HCl-P 释放, 碱性促进 $\mathrm{NaOH}-\mathrm{P}$ 释放, 中性时释放量最小 ${ }^{[4]}$. 太湖、滇池、西湖等湖泊磷迁移也呈现类似的规律 ${ }^{[42]}$. 但 $\mathrm{Gao}^{[36]}$ 发现天 找湖沉积物在 $\mathrm{pH}$ 为 10 时释放少量的磷 ( $\mathrm{pH}$ 为 $3 、 9$ 时释放大量的磷), 推测是因为天鹅湖 $\mathrm{Ca}^{2+}$ 浓度较高 $(0.44 \mathrm{~g} / \mathrm{L})$, 释放的磷会重新被吸附或形成共沉淀.

Wang 等 ${ }^{[37]}$ 发现温度升高会促进红枫湖底泥 NaOH-P 的迁移, 这是因为适当升温可以加强微生物活性 和有机质矿化速率,该过程消耗溶解氧会促进 $\mathrm{NaOH}-\mathrm{P}$ 的释放; 有机质矿化生成的有机酸能螯合铁铝等金 属, 从而促进金属结合态磷的释放 ${ }^{[5]}$. Liu 等 ${ }^{[45]}$ 借助 DGT 和 Peeper 探究温度对太湖沉积物磷迁移的影响, 与 $7^{\circ} \mathrm{C}$ 相比, $25^{\circ} \mathrm{C}$ 时模拟实验中 DGT 活性磷和 SRP 分别增加了 $279 \%$ 和 $125 \%$, 野外调查中分别增加了 $460 \%$ 和 $189 \%$, 分析发现温度会影响微生物的活性和藻类的降解, 进而影响磷的释放. 高温下沉积物磷释放量通 常高于低温时, 这也许是许多湖泊在高温季节富营养化程度加强的原因之一.

硝酸盐作为电子受体能影响铁的氧化还原循环, 进而影响磷的迁移 ${ }^{[38]}$. 相比于溶解氧, 硝酸盐溶解度 更高、渗透深度更深, 但硝酸盐可能会加速湖泊富营养化. 野外调查和模拟实验均发现硝酸盐能抑制 Fe-P 的还原, 从而抑制 Mathews 湖沉积物释放磷 ${ }^{[39]}$. Hemond 等 ${ }^{\left[{ }^{[3]}\right]}$ 发现 Upper Mystic 湖热分层期间,湖体垂向上 当硝酸盐浓度接近零时, 磷和铁浓度会突增, 推测硝酸盐能够抑制缺氧湖泊下层沉积物释磷. Hansen 等 ${ }^{[40]}$ 向上覆水添加硝酸盐抑制了 Vedsted 湖沉积物释磷, 这利用了硝酸盐氧化有机质的能力 (反硝化作用). 有学 者认为当深水湖泊和浅水湖泊硝酸盐浓度达到 1.0 和 $0.5 \mathrm{mg} / \mathrm{L}$ 时就能抑制沉积物释磷, 这一结论过于片 面, 如果界面磷迁移主要受 $\mathrm{pH}$ 驱动, 而不是氧化还原时, 添加硝酸盐可能会增加 $\mathrm{pH}$, 从而促进磷的释放 ${ }^{[41]}$. 此外, 有研究发现硝酸盐还能促进铁还原细菌的生长, 一旦硝酸盐耗尽, $\mathrm{Fe}^{3+}$ 作为替代电子受体会加速 $\mathrm{NaOH}-\mathrm{P}$ 释放 ${ }^{[41]}$.

\section{3 生物对沉积物一水界面磷迁移转化的影响}

有学者发现蓝藻等浮游植物的生长能促进沉积物磷的释放 ${ }^{[1,46]}$, 一方面, 浮游植物同化吸收上覆水中的 磷, 改变了沉积物与上覆水间磷的平衡, 另一方面, 浮游植物的生长会导致上覆水 $\mathrm{pH}$ 升高和氧化还原电位 降低, 从而促进沉积物磷向上覆水迁移 ${ }^{[1]}$, 此外, 有些浮游植物还能改变沉积物微生物群落结构来促进沉积 物磷迁移 ${ }^{[46]}$. Cao 等 ${ }^{[46]}$ 发现滇池沉积物释放的磷, $70.2 \%$ 会被蓝藻重新吸收,但藻的生长与磷的摄取并不同 步, 藻类奢侈吸收将磷储存在体内, 维持其在低磷环境中的生长 ${ }^{[3]}$. 磷会以有机磷的形式储存在生物体, 随 着浮游植物的衰亡, 磷会重新进人上覆水参加磷循环. 研究发现滇池蓝藻衰亡释放的磷占水体 TP 的 $96.7 \%$, 这部分磷或被沉积物吸附或为新一轮的藻华提供营养基础 ${ }^{[47]}$, 且衰亡形成的厌氧强还原环境会进一步加速 蓝藻的衰亡 ${ }^{[43]}$. 
作为湖泊初级生产力的重要贡献者, 不同水生植物对界面磷迁移的作用机制和影响效果也不同, 研究 发现苦草(Vallisneria spiralis) 与菖蒲 (Acorus calamus) 虽都能减少太湖梅梁湾沉积物磷的迁移速率, 但菖蒲 对总磷的抑制效果相对更好, 菖蒲的根系为微生物与菌胶团营造了适宜生境, 从而抑制 PP 和 DOP 的释放; 苦草通过同化吸收 DIP 以及改变环境溶解氧和 $\mathrm{pH}$, 从而影响界面磷素循环 ${ }^{[48]}$. 易文利等 ${ }^{[49]}$ 发现穗花狐尾 藻 (Myriophyllum spicatum) 的生长促进沉积物中活性有机磷和 $\mathrm{NaOH}-\mathrm{P}$ 的释放, 衰亡过程则以磷的沉积为主.

底栖动物的爬行、摄食、避敌和潜穴等生理活动均会影响沉积物性质 (如粒径、孔隙度和沉积能力等), 进而影响界面磷迁移 ${ }^{[50-52]}$. 常见的底栖动物有摇蚊幼虫 ( chironomid larvae)、水丝蚓( Tubificid worms) 和河蚬 (Corbicula fluminea) 等, 如摇蚊幼虫能增加沉积物中溶解氧的渗透深度, 促进 $\mathrm{Fe}(\mathrm{OH})_{3}$ 的生成, 从而抑制沉 积物中活性磷的释放 ${ }^{[50]}$. 水丝蚓活动会增加沉积物含水率和氧化还原电位, 研究发现水丝蚓对太湖梅梁湾 和大浦口沉积物磷迁移作用效果相反, 可能是因为大浦口间隙水 $\mathrm{Fe}^{2+}$ 浓度是梅梁湾的数倍 ${ }^{[51]}$. 但有学者发 现河蚬扰动促进了大浦口沉积物活性磷的释放, 这是因为河蚬扰动促进了有机质和含磷代谢产物的分解, 这些过程释放的磷远大于氢氧化铁吸附的磷 ${ }^{[52]}$.

\section{4 浅水湖泊与深水湖泊磷迁移主要影响机制的差异}

与深水湖泊相比, 浅水湖泊沉积物一水界面溶解氧较充足, 易形成氧化层阻碍磷的迁移 ${ }^{[25]}$. 然而, 浅水 湖泊由于湖体较浅, 风浪等扰动易引起表层沉积物再悬浮, 沉积物磷的迁移与再悬浮的强度、频率、时间密 切相关 ${ }^{[27]}$. 统计发现太湖这一典型浅水湖泊,一年中持续 $1 \mathrm{~h}$ 风速在 $8 \mathrm{~m} / \mathrm{s}$ 以上的天数多达 $125 \mathrm{~d}$, 这使得风 浪扰动作为太湖沉积物磷迁移的主导因素, 备受关注 ${ }^{[28]}$. 野外调查发现风浪扰动会引起沉积物磷的暴发性 释放, 风浪初期水体 SRP 浓度是静风期的 2 倍, 但随着风浪的继续, 水体 SRP 浓度明显下降, 风浪过后, 水体 中磷浓度重新恢复到低水平, 可能由于大风浪会引起水体颗粒物和溶解氧的升高以及水体其他理化性质的 改变 ${ }^{[28]}$.

深水湖泊易受温度影响而产生季节性分层, 夏季光照辐射较强时, 湖体自上而下分为湖上层、温跃层和 湖下层 ${ }^{[53]}$. 湖上层因藻类光合作用, 水体 $\mathrm{pH}$ 和 $\mathrm{DO}$ 浓度较高 ${ }^{[33-54]}$. 湖下层受温度和光照的限制, 藻类光合 作用较弱, 水体难以及时复氧; 有机质分解也会耗氧, 使得深水湖泊沉积物一水界面常缺氧或厌氧 ${ }^{[54]}$. 湖下 层有机质分解产生的酸性物质会影响界面 $\mathrm{pH}$, 增加沉积物释磷风险. 但受温跃层的影响, 沉积物释放的磷 在湖下层积累而无法向湖上层补给 ${ }^{[53]}$, 湖上层的氧也难以向湖下层传递.

一些富营养化浅水湖泊沉积物在夏季会向上覆水释放大量的磷, 在水流混合作用下, 磷进人真光层, 供 给浮游植物的生长; 浮游植物利用自身生理特性 “奢侈吸收” 真光层的磷, 又会间接促进沉积物释磷, 浮游植 物吸磷与沉积物释磷相互促进, 导致湖泊富营养化加剧. 深水湖泊受温跃层的影响, 沉积物释放的磷仅在湖 下层迁移, 温跃层的静力稳定度较大, 磷难以进人湖泊真光层供浮游植物利用, 内源磷对湖泊磷循环的贡献 有限. 因此, 沉积物内源磷对浅水湖泊的影响比深水湖泊大.

\section{3 沉积物一水界面磷迁移的研究方法}

沉积物和上覆水间频繁地发生着磷的交换, 涉及了吸附/解吸、悬浮/沉降、络合/解离和磷的生物循环 等过程 ${ }^{[44]}$, 这使得研究磷的迁移规律变得尤为复杂. 现阶段, 学者们常利用野外调查、模拟实验、质量衡算 和模型等方法探究沉积物一水界面磷的迁移规律和影响机制 (表 1).

\section{1 实验方法}

实验方法包括野外调查和模拟实验. 野外调查通过长时间调查特定湖泊的相应指标, 分析磷的时空分 布特征, 但对磷迁移机制的研究不适用 ${ }^{[2]}$. 由于湖泊的异质性, 单一湖泊的研究结果往往无法得到普适性推 论, 需要以大量监测数据为基础识别磷的迁移过程. 但野外调查的工作量很大, 受样点布设、采样频次和测 定方法等因素的影响,调查结果存在不确定性 ${ }^{[23]}$.

前人利用模拟实验探究了磷的形态分布 ${ }^{[19]}$ 、迁移过程 ${ }^{[15]}$ 、驱动机制 ${ }^{[32-43]}$ 以及释放通量 ${ }^{[57-59]}$ 等科学问 题, 取得了一定进展. 现阶段, 模拟实验可通过表层沉积物模拟 ${ }^{[4]}$ 、流动培养 ${ }^{[19]}$ 、柱状芯样模拟 ${ }^{[23]}$ 和水下原 位培养等方法进行. 表层沉积物模拟法利用抓斗抓取表层沉积物进行静态或动态培养, 但在采样和培养过 程中可能会破坏沉积物理化性质, 实验结果只能用作定性分析. 柱状芯样法由于可以控制实验条件, 且柱状 
表 1 不同湖泊沉积物磷释放速率和通量

Tab.1 Releasing rates and fluxes of sediment phosphorus in different lakes

\begin{tabular}{|c|c|c|c|c|c|}
\hline 湖泊 & $\begin{array}{c}\text { 释放速率/ } \\
\left(\mathrm{mg} /\left(\mathrm{m}^{2} \cdot \mathrm{d}\right)\right)\end{array}$ & $\begin{array}{c}\text { 释放通量/ } \\
(\mathrm{t} / \mathrm{a})\end{array}$ & 研究方法 & 备注 & 文献 \\
\hline 太湖 (东太湖) & $2.06 \pm 1.71$ & - & 静态模拟实验 & 年平均 & {$[14]$} \\
\hline 太湖 (梅梁湾) & $0.53 \pm 0.52$ & - & 静态模拟实验 & 年平均 & {$[14]$} \\
\hline 红枫湖 & - & $28.85 \sim 357.8$ & 野外调查 & - & {$[17]$} \\
\hline 红枫湖 & $0.41 \sim 0.87$ & 12.9 & 静态模拟实验 & $14 \sim 16^{\circ} \mathrm{C}$ 培养 & {$[17]$} \\
\hline 红枫湖 & $118.00 \sim 226.00$ & $7.335(120 \mathrm{~d})$ & 扩散模型法 & 夏季, 结合 DGT 法 & {$[17]$} \\
\hline 滇池 & - & 82.39 & 数值模型法 & 三维数值模型 & {$[18]$} \\
\hline 滇池 & - & $74.9 \sim 380.2$ & 静态模拟实验 & - & {$[18]$} \\
\hline 南四湖 & $0.30 \sim 2.70$ & - & 静态模拟实验 & 避光室温培养 & {$[53]$} \\
\hline 南四湖 & $0.24 \sim 0.66$ & - & 扩散模型法 & 结合 Peeper 法 & {$[53]$} \\
\hline 南四湖 & $0.04 \sim 0.51$ & - & 扩散模型法 & 结合离心法 & {$[53]$} \\
\hline 滇池 (福保湾) & $0.90 \sim 2.06$ & $0.79 \pm 0.53$ & 静态模拟实验 & $5 、 15 、 25^{\circ} \mathrm{C}$ 培养 & {$[54]$} \\
\hline 滇池 (福保湾) & $0.118 \sim 0.265$ & $0.081 \pm 0.001$ & 扩散模型法 & 结合 Peeper 法 & {$[54]$} \\
\hline
\end{tabular}

沉积物受干扰较少, 被学者们广泛应用. 但柱状芯样法体系较小, 易产生边壁效应, 且无法模拟实际环境颗 粒物沉降和沉积物再悬浮对磷迁移的影响 ${ }^{[59]}$. 水下原位实验直接在湖泊围隔一个实验区域, 使实验条件更 接近自然状态,但由于对配套设施要求高,费用高,应用受到限制 ${ }^{[55]}$.

模拟实验仅反映了磷迁移的短期效应, 而自然状态下沉积物磷迁移是一个漫长的过程, 期间湖泊的环 境和生物等因子均会改变. 此外, 模拟实验也无法模拟出自然状态下的水文特征, 而水动力扰动引起的颗粒 物沉降和沉积物再悬浮均会影响磷的迁移, 这些因素均会导致实验结果与实际情况有所偏差. 因此, 未来可 以将模拟实验与野外调查相结合, 通过野外调查在宏观上识别磷的实际迁移过程, 再结合模拟实验在微观 尺度上验证磷的迁移规律和驱动机制.

\section{2 数学方法}

磷迁移的数学研究方法包括质量衡算法和模型法. 质量衡算法 ${ }^{[2]}$ 通过调查湖泊生态系统中磷的输人输 出量, 从季节或年际尺度上估算湖泊内源磷负荷. 由于质量衡算法需要以长时间的野外调查数据为基础, 受 样点设置、采样频次及检测分析等主观因素的影响, 对外源负荷的估算可能存在偏差, 此外, 通过质量衡算 也无法了解湖泊内源磷的分布状况, 因此, 该方法仅在没有沉积物磷通量数据时使用.

通过野外调查和室内模拟了解磷的迁移过程和影响因子, 在此基础上, 建立模型探讨磷的迁移规律及 各过程对磷循环的贡献 ${ }^{[24]}$. 谢兴勇等 ${ }^{[55]}$ 利用以质量平衡为基础的水生态动力学模型 (CAEDYM) 模拟太湖 磷的循环过程及磷对浮游植物生长的影响, 发现水温、溶解氧、 $\mathrm{TP} 、 \mathrm{PO}_{4}^{3-}$ 和叶绿素 $\mathrm{a}$ 等模拟结果与太湖野外 调查结果相似, 且对浮游植物优势种演替的预测也与相关研究成果基本一致, 表明该模型适用于研究浅水 湖泊磷循环. 邹锐等 ${ }^{[24]}$ 利用三维水质模型研究滇池磷通量时, 认为沉降是磷的主要输出过程, 占湖泊总磷 输出的 $62.77 \%$. CE-QUAL-ICM 模型考虑了藻类生长、呼吸和代谢对藻华与营养盐相互作用的影响, 将其与 三维水动力模型 $\left(\mathrm{EFDC}\right.$ ) 耦合, 能够很好地模拟乌梁素海中藻类、TN、TP 和 COD 的年际变化规律 ${ }^{[56]}$. 相比 于质量衡算法, 模型法能够识别磷的迁移过程, 并估计其对湖泊磷循环的贡献 ${ }^{[24]}$, 但由于模型法参数较多且 取值困难, 将模型运用到特定湖泊需要不断试差来拟合湖泊实际磷的迁移过程.

此外,间隙水扩散模型法将 Fick 定律与间隙水被动采用技术 (Rhizon、Peeper、DGT 和 DET 等) 相结合, 常用来估算沉积物一水界面磷通量 ${ }^{[57-59]}$. 罗婧等 ${ }^{[57]}$ 借助 ZrO-DGT 技术测定间隙水磷的含量, 以此估算红枫 湖热分层期间沉积物磷释放通量, 发现其多达 6270 7999 kg, 占全湖磷负荷的 22\% 28\%. 研究发现模拟实 验的结果比间隙水扩散模型法更接近实际, 可能是因为间隙水扩散模型法仅能估算静态释放通量 ${ }^{[58-59]}$. 钱 宝等 ${ }^{[60]}$ 利用间隙水扩散模型法研究大纵湖、蜈蚣湖和九龙口沉积物一水界面磷迁移, 发现疏浚后的九龙口 沉积物磷主要是离子态的, 可通过浓度梯度扩散释放; 而大纵湖和蜈蚣湖沉积物中磷以可交换态磷为主, 主 
要受氧化还原电位的影响而释放.

现阶段, 沉积物一水界面磷迁移可采用野外调查、模拟实验、质量衡算和模型等研究方法, 常根据研究目 的来选择研究方法. 野外调查可以在宏观上分析湖泊过去和现在的实际情况, 但无法识别驱动机制. 模拟实 验广泛用于驱动机制 ${ }^{[4-5]}$ 、迁移过程 ${ }^{[46]}$ 和释放通量 ${ }^{[57-60]}$ 的研究, 受实验体系大小的限制, 仅能反映磷的短期 释放效应, 实验结果可能与实际有所偏差. 模型法除了可以验证磷的迁移机制 ${ }^{[2]}$ 和量化特定迁移过程对湖 泊磷循环的贡献 ${ }^{[24]}$, 还能预测磷的迁移过程. 模型的构建需要以野外调查和模拟实验的研究成果为基础, 并对选定的参数不断率定校正, 使选定的模型符合特定湖泊. 因此, 未来可以将模拟实验、野外调查和模型 相结合, 深人探究湖泊磷的迁移过程、驱动机制以及预测磷的迁移趋势.

\section{4 研究展望}

现阶段, 由于对富营养湖泊内源磷的作用机制和影响程度认识不足, 导致湖泊富营养化治理措施因缺 乏科学指导而停滞不前. 湖泊磷循环是一个复杂过程, 沉积物一水界面作为磷循环的重要场所也备受关注, 但目前有许多机制尚未被人们认识,从发展趋势来看,未来可从以下几个方面继续开展研究:

1) 探索能够表征有机磷、多聚磷酸盐、低价态磷等形态磷的新技术新手段, 为进一步研究磷的赋存形 态、迁移规律以及生物有效性提供技术支撑. 目前常用的顺序提取法, 仅能分离鉴定沉积物中无机磷, 受研 究方法限制, 有机磷常当作一个整体研究. 因此, 研发能够表征各形态有机磷的技术, 从而探究有机磷在沉 积物一水界面的迁移转化及其对上覆水磷浓度的贡献显得尤为必要. 虽然 ${ }^{31}$ P-NMP 是一个很好的检测手段, 但仍存在许多不足,未来可从完善提取技术流程、降低成本和扩大应用领域等方面深人研究.

2) 深化多因素耦合作用下沉积物一水界面磷迁移规律和驱动机制的研究. 沉积物一水界面作为磷环境 地球化学循环的重要场所, 频繁地发生着磷的交换. 沉积物性质(如粒径分布、有机质含量等)、环境因子(溶 解氧、温度、 $\mathrm{pH}$ 等) 及生物 (浮游植物、水生动植物等) 等因素相互作用, 共同影响着磷的迁移转化. 目前对沉 积物一水界面磷的迁移转化机制有了一定的认识, 但研究多局限于单因素和定性方面的研究, 而对多因素耦 合作用下磷迁移定量研究还相对欠缺, 未来可进一步探究多因素耦合作用下沉积物一水界面磷的迁移转化 规律, 如探究溶解氧和 $\mathrm{pH}$ 耦合作用下, 何种因子是主导影响机制, 各因子对磷迁移的贡献是多少, 各因子间 是协同作用还是拮抗作用, 以及磷的迁移规律.

3) 将模拟实验、野外调查和模型法相结合深人探究磷的迁移规律. 野外调查、模拟实验、质量衡算和模 型等方法均能用于沉积物一水界面磷迁移的研究, 各有优劣, 可根据研究目的选择不同的研究方法. 野外调 查可用于分析湖泊实际磷迁移过程, 但耗时耗力, 且无法进行机制的研究; 模拟实验可控制实验条件, 被广 泛用于机制和规律的研究, 但体系较小且仅能反应磷的短期迁移过程; 模型法可分析磷的迁移规律、量化各 迁移过程对磷循环的贡献, 甚至是预测磷的迁移过程, 但模型的构建很复杂, 需以野外调查和模拟实验为基 础, 不断率定校正参数以适应特定湖泊的研究. 因此, 将野外调查、模拟实验和模型法相结合, 取长补短, 深 人探究湖泊磷的迁移规律, 以期为预防湖泊生态退化和修复富营养化湖泊提供理论依据和科学支持.

\section{5 参考文献}

[ 1 ] Chen M, Ding S, Chen X et al. Mechanisms driving phosphorus release during algal blooms based on hourly changes in iron and phosphorus concentrations in sediments. Water Research, 2018, 133: 153-164. DOI: 10.1016/j. watres. 2018. 01.040 .

[ 2 ] Wu Z, Wu SF, Liu Y et al. Key processes and mechanisms of nitrogen and phosphorus cycling in lakes. Acta Scientiarum Naturalium Universitatis Pekinensis, 2018, 54(1) : 218-228. DOI: 10.13209/j.0479-8023.2017.143. [吴桢，吴思枫， 刘永等. 湖泊氮磷循环的关键过程与定量识别方法. 北京大学学报: 自然科学版, 2018, 54(1): 218-228.]

[ 3 ] Yang Z. Advances in factors influencing release of nitrogen and phosphorus in sediments. Environmental Science Survey, 2017, 36 (A1) : 16-19, 29. [杨赵. 湖泊沉积物中氮磷源-汇现象影响因素研究进展. 环境科学导刊, 2017,36 (A1) : 16-19, 29.]

[ 4 ] Wu Y, Wen Y, Zhou J et al. Phosphorus release from lake sediments: Effects of $\mathrm{pH}$, temperature and dissolved oxygen. Journal of Civil Engineering, 2014, 18(1) : 323-329. DOI: 10.1007/s12205-014-0192-0. 
[ 5 ] Zhang Y, Liu ZS, Zhang YL et al. Effects of varying environmental conditions on release of sediment phosphorus in west lake, Hang Zhou, China. Acta Hydrobiologica Sinica, 2017, 41(6) : 1354-1361. DOI: 10.7541/2017.167. [张义, 刘子 森, 张圭否等. 环境因子对杭州西湖沉积物各形态磷释放的影响. 水生生物学报, 2017, 41(6) : 1354-1361.]

[ 6 ] Schindler DW, Carpenter SR, Chapra SC et al. Reducing phosphorus to curb lake eutrophication is a success. Environmental Science and Technology, 2016, 50(17) : 8923-8929. DOI: 10.1021/acs.est.6b02204.

[ 7 ] Conley DJ, Paerl HW, Howarth RW et al. Controlling eutrophication: nitrogen and phosphorus. Science, 2009, 323: 1014-1015. DOI: org/10.1126/science.1167755.

[ 8 ] Søndergaard M, Jensen JP, Jeppesen E. Role of sediment and internal loading of phosphorus in shallow lakes. Hydrobiologia, 2003, 506: 135-145. DOI: 10.1023/B:HYDR.0000008611.12704.dd.

[ 9 ] Smith L, Watzin MC, Druschel G. Relating sediment phosphorus mobility to seasonal and diel redox fluctuations at the sediment-water interface in a eutrophic freshwater lake. Limnology and Oceanography, 2011, 56 (6) : 2251-2264. DOI: 10.4319/lo.2011.56.6.2251.

[10] Xie P. Biological mechanisms driving the seasonal changes in the internal loading of phosphorus in shallow lakes. Science in China: Series D, 2005, 35( z2) : 11-23. [谢平. 浅水湖泊内源磷负荷季节变化的生物驱动机制. 中国科学: D 辑, $2005, \mathbf{3 5}(\mathrm{z} 2): 11-23$.

[11] Qian YC. Characteristics of phosphorus transformation in sediments of shallow lake and the mechanisms of biological effects on phosphorus transfor process: a case study of West Lake, Hangzhou [Dissertation]. Hangzhou: Zhejiang University, 2011. [ 钱秩超. 浅水湖泊沉积物磷素迁移转化特征与生物作用影响机制研究——以杭州西湖为例 [ 学位论文]. 杭州: 浙江大学, 2011.]

[12] Wu FC, Jin XC, Zhang RY et al. Effects and significance of organic nitrogen and phosphorus in the lake aquatic environment. J Lake Sci, 2010, 22(1) : 1-7. DOI: 10.18307/2010.0101. [吴丰昌, 金相灿, 张润宇等. 论有机氮磷在湖泊 水环境中的作用和重要性. 湖泊科学, $2010,22(1): 1-7$.

[13] Wang HJ, Cao RX, Zhang J et al. The non-negligible phosphorus form-reduced phosphorus in water. Sustainable Development , 2011, 1(2) : 59-64. DOI: org/10.12677/sd.2011.12010. [王红军, 曹瑞香, 张娟等. 水环境中不容忽视的磷 形态一低价磷酸盐. 可持续发展, 2011, 1(2) : 59-64.]

[14] Xu CX, Yuan J, Wang YP et al. Speciation and release mechanism of phosphorus in sediments and analysis methods for sequential extraction. Rock and Mineral Analysis, 2011, 30(6) : 785-794. [许春雪, 袁建, 王亚平等. 沉积物中磷的赋 存形态及磷形态顺序提取分析方法. 岩矿测试, 2011, 30(6) : 785-794.]

[15] Liu J, Luo X, Zhang N et al. Phosphorus released from sediment of Dianchi Lake and its effect on growth of Microcystis aeruginosa. Environmental Science and Pollution Research, 2016, 23 (16) : 16321-16328. DOI: 10.1007/s11356-0166816-9.

[16] Wang JF, Chen JA, Yang HQ et al. Bioavailable phosphorus in sediments from Lake Hongfeng, Southwestern China. Earth and Environment, 2016, 44(4) : 437-440. [王敬富, 陈敬安, 杨海全等. 贵州红枫湖沉积物磷的生物有效性研究. 地球与环境, 2016, 44(4): 437-440.]

[17] Xu Y, Chen JA, Wang JF et al. The micro-scale investigation on the effect of redox condition on the release of the sediment phosphorus in Lake Hongfeng. J Lake Sci, 2016, 28(1) : 68-74. DOI: 10.18307/2016.0108. [徐洋, 陈敬安, 王敬富 等. 氧化还原条件对红枫湖沉积物磷释放影响的微尺度分析. 湖泊科学, 2016, 28(1): 68-74.]

[18] Zhu GW, Qin BQ, Zhang L. Phosphorus fraction and algae availability in lake sediments from the middle and lower reaches of the Yangtze River. Science in China: Series D, 2005, 35(S2) : 24-32. [ 朱广伟, 秦伯强, 张路. 长江中下游湖 泊沉积物中磷的形态及藻类可利用量. 中国科学: D 辑, 2005, 35(S2) : 24-32.]

[19] Gao CM, Zhang ZF, Zhang S. Speciation and bioavailability of phosphorus in sediments (autumn) of Haizhou Bay. China Environmental Science, 2018, 38(4) : 1499-1509. [高春梅, 张中发, 张硕. 海州湾秋季沉积物磷的形态分布及生物 有效性. 中国环境科学, 2018, 38(4): 1499-1509.]

[20] Zhang L, Fan CX, Wang JJ et al. Space-time dependent variances of ammonia and phosphorus flux on sediment water interface in Lake Taihu. Environmental Science, 2006, 27(8): 1537-1543. [张路, 范成新, 王建军等. 太湖水土界面氮 磷交换通量的时空差异. 环境科学, 2006, 27(8): 1537-1543.]

[21] Zhang L, Fan CX, Zhu GW et al. Distribution of bioavailable phosphorus (BAP) in lake sediments of the middle and lower reaches of the Yangtze River. J Lake Sci, 2006, 18(1) : 36-42. DOI: 10.18307/2006.0105. [张路, 范成新, 朱广伟 
等. 长江中下游湖泊沉积物生物可利用磷分布特征. 湖泊科学, 2006, 18(1): 36-42.]

[22] Xu WL, Wang XR, Xian QM et al. Assessment the influence of P availability of sediments in Lake Taihu to Microcystis aeruginosa using different methods. China Environmental Science, 2011, 31(9): 1486-1491. [徐望龙, 王晓蓉, 鲜啟鸣 等. 不同方法测定沉积物中生物可利用性磷对铜绿微囊藻生长量的影响. 中国环境科学, 2011, 31 (9): 1486-1491.]

[23] Wang JF, Chen JA, Luo J et al. Comparative study on quantitative estimations of phosphorus release flux from sediments of Lake Hongfeng, Guizhou Province, China. Earth and Environment, 2018, 46(1): 1-6. [王敬富, 陈敬安, 罗婧等. 红 枫湖沉积物内源磷释放通量估算方法的对比研究. 地球与环境, 2018, 46(1): 1-6.].

[24] Zou R, Wu Z, Zhao L et al. Nutrient cycling flux of Lake Dianchi: A three-dimensional water quality modelling approach. J Lake Sci, 2017, 29(4) : 819-826. DOI: 10.18307/2017.0405. [邹锐, 吴桢, 赵否等. 湖泊营养盐通量平衡的三维 数值模拟. 湖泊科学, $2017,29(4): 819-826$.

[25] Qin BQ, Hu WP, Gao G et al. The dynamic mechanism of sediment suspension in Lake Taihu and the conceptual model of endogenous release. Chinese Science Bulletin, 2003, 48(17) : 1822-1831. [秦伯强, 胡维平, 高光等. 太湖沉积物悬浮 的动力机制及内源释放的概念性模式. 科学通报, 2003, 48(17): 1822-1831.]

[26] Tammeorg O, Horppila J, Laugaste R et al. Importance of diffusion and resuspension for phosphorus cycling during the growing season in large, shallow Lake Peipsi. Hydrobiologia, 2015, 760 (1) : 133-144. DOI: 10. 1007/s10750-0152319-9.

[27] Zheng XL, Zhang JJ, Chen L. Advances in the study of migration and transformation mechanisms of endogenous phosphorus via sediment resuspension. Advances in Water Science, 2013, 24(2) : 287-295. [郑西来, 张俊杰, 陈蕾. 再悬浮条件 下沉积物内源磷迁移-转化机制研究进展. 水科学进展, 2013, 24(2): 287-295.]

[28] Zhu GW, Qin BQ, Gao G. Direct evidence of violent release of endogenous phosphorus from large shallow lakes caused by wind and waves disturbance. Chinese Science Bulletin, 2005, 50(1) : 66-71. DOI : 10.1360/csb2005-50-1-66. [朱广伟, 秦伯强, 高光. 风浪扰动引起大型浅水湖泊内源磷暴发性释放的直接证据. 科学通报, 2005, 50(1): 66-71.]

[29] Zhao HC, Wang SR, Zhang L et al. Effect of OM content and constituents on phosphorus adsorption-release of the sediment from Erhai Lake. Acta Scientiae Circumstantiae, 2014, 34(9) : 2346-2354. DOI: 10.13671/j.hjkxxb.2014.0599. [赵海超, 王圣瑞, 张莉等. 有机质含量及其组分对洱海沉积物磷吸附-释放影响. 环境科学学报, 2014, 34(9): 2346-2354.]

[30] Li J, Zhang Y, Katsev S. Phosphorus recycling in deeply oxygenated sediments in Lake Superior controlled by organic matter mineralization. Limnology and Oceanography, 2018, 63: 1372-1385. DOI: 10.1002/lno.10778.

[31] Zhang Y, Wang SR, Duan CQ et al. Spatial-temporal variations of nitrogen and phosphorus forms in sediment pore-water as affected by submerged plant in Lake Dianchi. J Lake Sci, 2018, 30(2) : 314-325. DOI: 10.18307/2018.0204. [张云, 王圣瑞, 段昌群等. 滇池沉水植物生长过程对间隙水氮、磷时空变化的影响. 湖泊科学, 2018, 30(2) : 314-325.]

[32] Li L, Wang SR, Jiao LX et al. Vertical variation of phosphorus forms in Lake Dianchi and contribution to release. Environmental Science, 2016, 37(9) : 3384-3393. DOI: 10.13227/j.hjkx.2016.09.017. [李乐, 王圣瑞, 焦立新等. 滇池柱状 沉积物磷形态垂向变化及对释放的贡献. 环境科学, 2016, 37(9) : 3384-3393.]

[33] McMahon KD, Read EK. Microbial contributions to phosphorus cycling in eutrophic lakes and wastewater. Annual Review of Microbiology, 2013, 67: 199-219. DOI: 10.1146/annurev-micro-092412-155713.

[34] Qian Y, Chen ZJ, Wu DX et al. Effects of microorganisms on phosphorus release from sediment of eutrophic lake. Environmental Science and Technology, 2016, 39(4): 35-40. [ 钱燕, 陈正军, 吴定心等. 微生物活动对富营养化湖泊底泥 磷释放的影响. 环境科学与技术, 2016, 39(4) : 35-40.]

[35] Gong MD, Jin ZF, Wang Y et al. Coupling between iron and phosphorus in sediments of shallow lakes in the middle and lower reaches of Yangtze River using diffusive gradients in thin films (DGT). J Lake Sci, 2017, 29(5): 1103-1111. DOI: $10.18307 / 2017.0508$. [龚梦丹, 金增锋, 王燕等. 长江中下游典型浅水湖泊沉积物水界面磷与铁的堣合关 系. 湖泊科学, 2017, 29(5): 1103-1111.]

[36] Gao L. Phosphorus release from the sediments in Rongcheng Swan Lake under different pH conditions. Procedia Environmental Sciences, 2012, 13: 2077-2084. DOI: 10.1016/j.proenv.2012.01.197.

[37] Wang J, Chen J, Din S et al. Effects of temperature on phosphorus release in sediments of Hongfeng Lake, southwest China: an experimental study using diffusive gradients in thin-films (DGT) technique. Environmental Earth Sciences, 2015, 
74(7) : 5885-5894. DOI: 10.1007/s12665-015-4612-3.

[38] Hemond HF, Lin K. Nitrate suppresses internal phosphorus loading in an eutrophic lake. Water Research, 2010, 44(12): 3645-3650. DOI: 10.1016/j.watres.2010.04.018.

[39] Beutel MW, Horne AJ, Taylor WD et al. Effects of oxygen and nitrate on nutrient release from profundal sediments of a large, oligo-mesotrophic reservoir, Lake Mathews, California. Lake and Reservoir Management, 2008, 24 (1) : 18-29. DOI: $10.1080 / 07438140809354047$.

[40] Hansen J, Reitzel K, Jensen HS et al. Effects of aluminum, iron, oxygen and nitrate additions on phosphorus release from the sediment of a Danish softwater lake. Hydrobiologia, 2003, 492(1-3) : 139-149. DOI: 10.1023/ A:1024826131327.

[41] Schausera I, Chorusa I, Lewandowskib J. Effects of nitrate on phosphorus release: comparison of two Berlin lakes. Hydrobiologica, 2006, 34(4) : 325-332. DOI: 10.1002/aheh.200500632.

[42] Liang Z, Liu Z, Zhen S et al. Phosphorus speciation and effects of environmental factors on release of phosphorus from sediments obtained from Taihu Lake, Tien Lake, and East Lake. Toxicological and Environmental Chemistry, 2015, 97 (3/ 4 ) : 335-348. DOI: 10.1080/02772248.2015.1050186.

[43] Hao J, Lian B, Liu H et al. The release of phosphorus from sediment to lake water induced by cyanobacterial blooms and phosphorus removal by cell harvesting. Geomicrobiology Journal, 2016, 33(3/4) : 348-353. DOI: 10.1080/01490451. 2015. 1069909.

[44] Bao LL, Li XY. Release and absorption characteristics of phosphorus in river sediment and their influential factors. Ecology and Environmental Sciences, 2017, 26(2) : 350-356. [鲍林林, 李叙勇. 河流沉积物磷的吸附释放特征及其影响因 素. 生态环境学报, 2017, 26(2) : 350-356.]

[45] Liu Q, Ding S, Chen X et al. Effects of temperature on phosphorus mobilization in sediments in microcosm experiment and in the field. Applied Geochemistry, 2018, 88: 158-166. DOI: 10.1016/j.apgeochem.2017.07.018.

[46] Cao X, Wang Y, He J et al. Phosphorus mobility among sediments, water and cyanobacteria enhanced by cyanobacteria blooms in eutrophic Lake Dianchi. Environmental Pollution, 2016, 219: 580-587. DOI: 10.1016/j.envpol.2016.06.017.

[47] Zhang S, Wang W, Zhang K et al. Phosphorus release from cyanobacterial blooms during their decline period in eutrophic Dianchi Lake, China. Environmental Science and Pollution Research, 2018. DOI: 10.1007/s11356-018-1517-1.

[48] Hua ZL, Kang BB, Wu D. Effects of Vallisneria spiralis and Acorus calamus on inhibition of phosphorus release from meiliang bay sediments. Environmental Science and Technology, 2013, 36(9):31-35. [华祖林, 康蓓蓓, 巫丹. 苦草与菖蒲 对太湖梅梁湾沉积物磷释放抑制的研究. 环境科学与技术, 2013, 36(9) : 31-35.]

[49] Yi WL, Wang SR, Yang SW et al. Influences of submerged vegetation Myriophyllum spicatum and carbon source addition on the forms of phosphorus in sediments. Ecology and Environment, 2011, 20(6/7): 1092-1096. [易文利, 王圣瑞, 杨 苏文等. 外加碳源及沉水植物对沉积物各形态磷的影响. 生态环境学报, 2011, 20(6/7) : 1092-1096.]

[50] Yang YQ, Liu L, Chen MS et al. Effect of chironomid larvae bioturbation on release of internal phosphorus in eutrophic lake. Journal of Hohai University: Natural Sciences, 2016, 44(6): 485-490. [杨艳青, 刘凌, 陈沐松等. 摇蚊幼虫生 物扰动对富营养化湖泊内源磷释放的影响. 河海大学学报: 自然科学版, 2016, 44(6): 485-490.]

[51] Zhang L, Gu XZ, Wang ZD et al. The influence of Tubificid worms bioturbation on the exchange of phosphorus across sediment-water interface in lakes. J Lake Sci, 2010, 22(5) : 666-674. DOI: 10.18307/2010.0507. [张雷, 古小治, 王兆德 等. 水丝蚓 (Tubificid worms) 扰动对磷在湖泊沉积物-水界面迁移的影响. 湖泊科学, 2010, 22(5): 666-674.]

[52] Zhang L, Gu XZ, Shao SG et al. Impacts of Asian Clams (Corbicula fluminea) on lake sediment properties and phosphorus movement. Environmental Science, 2011, 32(1): 88-95. [张雷, 古小治, 邵世光等. 河蚬 (Corbicula fluminea) 扰动对 湖泊沉积物性质及磷迁移的影响. 环境科学, 2011, 32(1) : 88-95.]

[53] Zhang L, Li QH, Huang GJ et al. Seasonal stratification and eutrophication characteristics of a deep reservoir, Longtan Reservoir in subtropical area of China. Environmental Science, 2015, 36(2) : 438-447. DOI: 10.13227/j.hjkx.2015.02. 010. [张垒, 李秋华, 黄国佳等. 亚热带深水水库一一龙滩水库季节性分层与富营养化特征分析. 环境科学, $2015,36(2)$ : 438-447.]

[54] Wang LJ, Yu H, Niu Y et al. Distribution characteristics of water temperature and water quality of fuxian lake during thermal stratification period in summer. Environmental Science, 2017, 38(4) : 1384-1392. DOI: 10.13227/j.hjkx.201607165. [王琳杰, 余辉, 牛勇等. 抚仙湖夏季热分层时期水温及水质分布特征. 环境科学, 2017, 38(4): 1384-1392.]

[55] Xie XY, Zu W, Qian X et al. Numerical study on the ecological dynamics of phosphorus circle in Taihu Lake. China Envi- 
ronmental Science, 2011, 31(5): 858-862. [谢兴勇, 祖维, 钱新等. 太湖磷循环的生态动力学模拟研究. 中国环境 科学, $2011,31(5): 858-862$.]

[56] Li X, Shi HS, Zhang SL et al. Numerical simulation of water quality based on environmental fluid dynamics code for grassalgae lake in Inner Mongolia. Acta Ecologica Sinica, 2013, 33(13) : 3987-3994. DOI: 10.5846/stxb201207241053. [李 兴, 史洪森, 张树礼等. 基于环境流体动力学模型的浅水草藻型湖泊水质数值模拟. 生态学报, 2013, 33(13): 3987-3994. ]

[57] Luo J, Chen JA, Wang JF et al. Estimation of the phosphorus flux from the sediment of Hongfeng Lake using the ZrO-Oxide Diffusive Gradient in Thin Films (ZrO-Oxide DGT) Technique. Bulletin of Mineralogy, Petrology and Geochemistry, 2015, 34(5): 1014-1020. [罗婧, 陈敬安, 王敬富等. 利用薄膜扩散梯度技术估算红枫湖沉积物磷释放通量. 矿物 岩石地球化学通报, 2015, 34(5): 1014-1020.]

[58] Wang ZQ, Li B, Liang RJ et al. Comparative study on endogenous release of nitrogen and phosphorus in Nansi Lake, China. Acta Scientiae Circumstantiae, 2013, 33(2) : 487-493. DOI: 10.13671/j.hjkxxb.2013.02.040. [王志齐, 李宝, 梁 仁君等. 南四湖内源氮磷释放的对比研究. 环境科学学报, 2013, 33(2) : 487-493.]

[59] Li B, Ding SM, Fan CX et al. Estimation of releasing fluxes of sediment nitrogen and phosphorus in Fubao Bay in Dianchi Lake. Environmental Science, 2008, 29(1) : 114-120. DOI: 10.13227/j.hjkx.2008.01.031. [李宝, 丁土明, 范成新等. 滇池福保湾底泥内源氮磷营养盐释放通量估算. 环境科学, 2008, 29(1) : 114-120.]

[60] Qian B, Liu L, Xiao X et al. The process of phosphorus release from lake sediments on the micro-interface. Journal of Hydraulic Engineering, 2014, 45(4) : 482-489. [ 钱宝, 刘凌, 肖潇等. 湖泊沉积物-水微界面上磷的释放过程研究. 水 利学报, 2014, 45(4): 482-489.] 